Case Report

\title{
Therapeutic Benefits of Tocilizumab Vary in Different Organs of a Patient with AA Amyloidosis
}

\author{
Masaru Matsui, ${ }^{1}$ Satoshi Okayama, ${ }^{1}$ Hideo Tsushima, ${ }^{1}$ Kenichi Samejima, ${ }^{1}$ \\ Tomoko Kanki, ${ }^{1}$ Ayako Hasegawa, ${ }^{1}$ Katsuhiko Morimoto, ${ }^{1}$ Yasuhiro Akai, ${ }^{1}$ \\ Masato Takano, ${ }^{2}$ Shiro Uemura, ${ }^{1}$ Chiho Ohbayashi, ${ }^{2}$ and Yoshihiko Saito ${ }^{1}$ \\ ${ }^{1}$ First Department of Internal Medicine, Nara Medical University, 840 Shijo-cho, Kashihara, Nara 634-8522, Japan \\ ${ }^{2}$ Department of Diagnostic Pathology, Nara Medical University, 840 Shijo-cho, Kashihara, Nara 634-8522, Japan \\ Correspondence should be addressed to Satoshi Okayama; satosi01@naramed-u.ac.jp
}

Received 13 May 2014; Revised 16 July 2014; Accepted 17 July 2014; Published 12 August 2014

Academic Editor: Mohsen Agharazii

Copyright (C) 2014 Masaru Matsui et al. This is an open access article distributed under the Creative Commons Attribution License, which permits unrestricted use, distribution, and reproduction in any medium, provided the original work is properly cited.

\begin{abstract}
Systemic reactive AA amyloidosis is a life-threatening complication of chronic inflammatory diseases. Anti-interleukin-6 receptor, tocilizumab (TCZ), has been shown to improve clinical symptoms of patients with AA amyloidosis, accompanied with regression of the amyloid deposition. We report a case of AA amyloidosis evaluated by histology of multiple organs before and after TCZ treatment. A woman in her 60s with rheumatoid arthritis was referred to our hospital because of cardiac and renal dysfunction. A gastric and renal biopsy revealed the deposition of AA amyloid, and echocardiography revealed concentric left ventricular hypertrophy. Her estimated glomerular filtration rate was decreased to $8.6 \mathrm{~mL} / \mathrm{min} / 1.73 \mathrm{~m}^{2}$, and B-type natriuretic peptide, Creactive protein, and serum amyloid A protein were significantly elevated. TCZ treatments markedly decreased her serum amyloid A protein and C-reactive protein levels, but hemodialysis was required 1 year later. Endoscopic gastric rebiopsy 3 years after initiation of TCZ treatments revealed the regression of amyloid deposition and echocardiography revealed improvement of her left ventricular hypertrophy. However, a renal rebiopsy revealed that the amyloid deposition had not regressed. In conclusion, these observations suggest that the therapeutic effects of TCZ can vary among organs in patients with AA amyloidosis.
\end{abstract}

\section{Introduction}

Systemic reactive AA amyloidosis is a life-threatening complication of chronic inflammatory diseases, such as rheumatoid arthritis (RA), latent tuberculosis, and bronchiectasis, and is characterized by the extracellular deposition of amyloid fibrils derived from serum amyloid A protein (SAA) [1]. SAA is synthesized in hepatocytes following stimulation by proinflammatory cytokines, such as interleukin- (IL-) 1 , IL-6, and tumor necrosis factor-alpha, suggesting that these cytokines are potential therapeutic targets for the treatment of AA amyloidosis $[2,3]$.

Tocilizumab (TCZ) is a humanized monoclonal antibody that competitively inhibits the binding of IL-6 to its receptor [4]. TCZ has been shown to suppress the activity of RA and to improve clinical symptoms of AA amyloidosis secondary to RA, such as diarrhea, proteinuria, and cardiac hypertrophy
[5-9]. However, few studies have reported the different therapeutic effects of TCZ on different organs or the comparative histology of multiple organs before and after TCZ treatment. Here, we describe a patient with AA amyloidosis who was treated with TCZ, after which her gastric manifestations improved; however, the renal amyloid deposition did not regress with treatment.

\section{Case Presentation}

A woman in 60s was referred to our hospital because of heart failure and renal dysfunction. She had suffered from RA for approximately 10 years, and its activity could not be sufficiently suppressed. She had been treated with prednisolone ( $7.5 \mathrm{mg} /$ day), bucillamine $(200 \mathrm{mg} /$ day $)$, and methotrexate ( $8 \mathrm{mg} /$ week), but she continued to experience joint pain in addition to having high levels of $\mathrm{C}$-reactive protein (CRP). 
She had been admitted to another hospital because of dyspnea 3 months before this presentation. Her renal function worsened, with her estimated glomerular filtration rate (eGFR) decreasing from 32.1 to $11.5 \mathrm{~mL} / \mathrm{min} / 1.73 \mathrm{~m}^{2}$. An endoscopic gastric biopsy revealed amyloid deposition in her stomach, indicating that her disease was complicated by amyloidosis (Figure 1(a)).

The patient had a regular tachycardia of 104 beats/min, an elevated blood pressure of $184 / 118 \mathrm{mmHg}$, and a normal temperature of $36.4^{\circ} \mathrm{C}$. Cardiac auscultation revealed a third heart sound without an obvious murmur. Slight peripheral leg edema was observed, and the joints of her hands and feet were swollen and deformed. Neurological findings were normal. Laboratory findings are shown in Table 1. Her urinalysis showed mild proteinuria, microscopic hematuria, and an occasional granular cast. A complete blood count analysis showed leukocytosis and anemia, and a biochemical analysis showed hypoalbuminemia, renal dysfunction with an eGFR of $8.6 \mathrm{~mL} / \mathrm{min} / 1.73 \mathrm{~m}^{2}$, and a high B-type natriuretic peptide concentration of $3002.5 \mathrm{pg} / \mathrm{mL}$. An immunological analysis revealed significant elevations in CRP and SAA levels; monoclonal immunoglobulins and free light chains were not detected in the patient's serum or urine.

An ultrasound examination indicated diffusely enlarged thyroid glands, although thyroid function was normal. A chest X-ray scan showed cardiac enlargement, pulmonary congestion, and bilateral pleural effusion, and transthoracic echocardiography revealed concentric left ventricular (LV) hypertrophy with a sparkling and granular myocardial texture and right ventricular hypertrophy. The patient's LV ejection fraction and diastolic dimension were preserved at $53 \%$ and $46 \mathrm{~mm}$, respectively; however, her left atrial diameter and septal and posterior wall thicknesses were significantly increased at $55 \mathrm{~mm}, 14.0 \mathrm{~mm}$, and $14.7 \mathrm{~mm}$, respectively. The LV mass had thus significantly increased to $256.6 \mathrm{~g}$, which was determined according to Devereux's formula (Figure 2) [10]. Peak early and late diastolic LV inflow velocities could not be measured by transmitral Doppler imaging because of their fusion associated with the sinus tachycardia. No significant valvular disease was detected. We suspected that she had heart failure with preserved ejection fraction due to cardiac amyloidosis; however, we did not perform percutaneous endomyocardial biopsy owing to the patient's refusal and her progressive renal failure. A renal biopsy revealed that approximately $40 \%$ of her glomeruli were globally sclerotic. Small arteries were severely injured by amyloid A deposition, and the tubules were focally atrophic (Figures 3(a)-3(c)). These findings confirmed a diagnosis of AA amyloidosis involving the stomach and kidney, and she was suspected of having cardiac amyloidosis. We considered that her prognosis could be improved by eliminating the amyloid deposition in multiple organs.

Diuretics and a low dose of angiotensin converting enzyme inhibitor were added to her treatment regimen, and TCZ ( $8 \mathrm{mg} / \mathrm{kg}$, repeated every 4 weeks) was administered, after receiving written informed consent. As a result, the patient's SAA and CRP levels were markedly decreased to within normal ranges after the first TCZ infusion, and her
TABLE 1: Laboratory findings on admission.

\begin{tabular}{|c|c|c|}
\hline \multicolumn{3}{|c|}{ Urinalysis } \\
\hline Protein & $1+$ & \\
\hline Occult blood & $1+$ & \\
\hline Glucose & - & \\
\hline \multicolumn{3}{|c|}{ Urine sediment } \\
\hline WBC & $1-4$ & /HPF \\
\hline $\mathrm{RBC}$ & $1-4$ & /HPF \\
\hline Granular casts & $1+$ & $/ \mathrm{LPF}$ \\
\hline \multicolumn{3}{|c|}{ Complete blood counts } \\
\hline WBC & 13600 & $/ \mathrm{mm}^{3}$ \\
\hline $\mathrm{RBC}$ & 355 & $\times 10^{4} / \mathrm{mm}^{3}$ \\
\hline Hemoglobin & 9.6 & $\mathrm{~g} / \mathrm{dL}$ \\
\hline Hematocrit & 29.9 & $\%$ \\
\hline Platelets & 81.9 & $\times 10^{4} / \mathrm{mm}^{3}$ \\
\hline \multicolumn{3}{|c|}{ Biochemistry } \\
\hline CRP & 3.4 & $\mathrm{mg} / \mathrm{dL}$ \\
\hline SAA & 32.3 & $\mu \mathrm{g} / \mathrm{mL}$ \\
\hline Total protein & 5.8 & $\mathrm{~g} / \mathrm{dL}$ \\
\hline Albumin & 3.2 & $\mathrm{~g} / \mathrm{dL}$ \\
\hline Glucose & 94 & $\mathrm{mg} / \mathrm{dL}$ \\
\hline Uric acid & 9.6 & $\mathrm{mg} / \mathrm{dL}$ \\
\hline BUN & 55 & $\mathrm{mg} / \mathrm{dL}$ \\
\hline Scr & 4.35 & $\mathrm{mg} / \mathrm{dL}$ \\
\hline eGFR & 8.6 & $\mathrm{~mL} / \mathrm{min} / 1.73 \mathrm{~m}^{2}$ \\
\hline Sodium & 139 & $\mathrm{mEq} / \mathrm{L}$ \\
\hline Potassium & 4.8 & $\mathrm{mEq} / \mathrm{L}$ \\
\hline Chloride & 106 & $\mathrm{mEq} / \mathrm{L}$ \\
\hline Serum $\beta 2-M G$ & 11.4 & $\mathrm{mg} / \mathrm{L}$ \\
\hline Urinary $\beta 2-\mathrm{MG}$ & 4189 & $\mu \mathrm{g} / \mathrm{L}$ \\
\hline \multicolumn{3}{|c|}{ Immunology } \\
\hline $\mathrm{RF}$ & 3.4 & $\mathrm{IU} / \mathrm{mL}$ \\
\hline ANA & - & \\
\hline Anti-CCP Ab & 3.4 & $\mathrm{U} / \mathrm{mL}$ \\
\hline MMP3 & 322 & $\mathrm{ng} / \mathrm{mL}$ \\
\hline Complement & 37 & $\mathrm{U} / \mathrm{mL}$ \\
\hline $\mathrm{C} 3$ & 62.4 & $\mathrm{mg} / \mathrm{dL}$ \\
\hline $\mathrm{C} 4$ & 20.6 & $\mathrm{mg} / \mathrm{dL}$ \\
\hline $\operatorname{Ig} A$ & $\begin{array}{c}269.2 \\
2\end{array}$ & $\mathrm{mg} / \mathrm{dL}$ \\
\hline IgG & 1119.9 & $\mathrm{mg} / \mathrm{dL}$ \\
\hline $\operatorname{IgM}$ & 76.8 & $\mathrm{mg} / \mathrm{dL}$ \\
\hline \multicolumn{3}{|c|}{ Endocrinology } \\
\hline HbAlc & 6.2 & $\%$ \\
\hline BNP & 3002.5 & $\mathrm{pg} / \mathrm{mL}$ \\
\hline
\end{tabular}

RBC: red blood cell; WBC: white blood cell; HPF: high-power field; CRP: C-reactive protein; SAA: serum amyloid A protein; BUN: blood urea nitrogen; Scr: serum creatinine; eGFR: estimated glomerular filtration ratio; $\beta 2$ MG: $\beta 2$-microglobulin; HbAlc: haemoglobin Alc; BNP: B-type natriuretic peptide; RF: rheumatoid factor; ANA: antinuclear antibody; antiCCP Ab: antibodies against cyclic citrullinated peptide; MMP3: matrix metalloproteinase 3; Ig: immunoglobulin. 


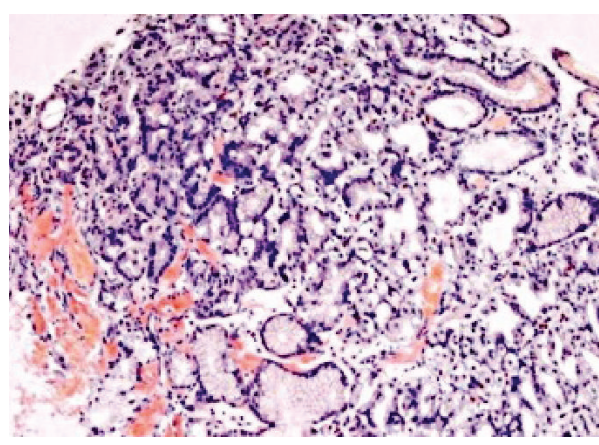

(a)

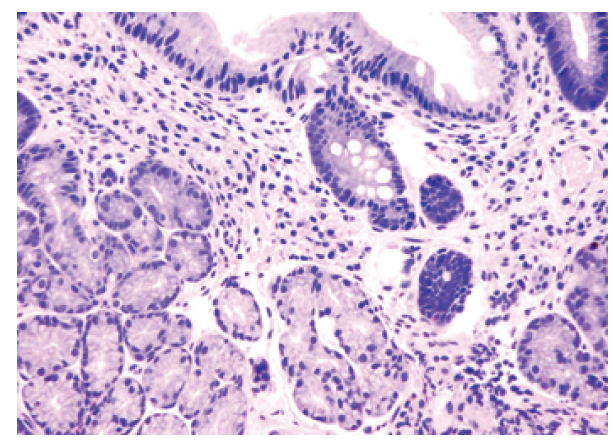

(b)

FIGURE 1: Endoscopic gastric biopsy. (a) Congo red staining shows amorphous amyloid deposits in the gastric mucosa. (b) After 4 years of tocilizumab treatments, regression of the amyloid deposition was noted.

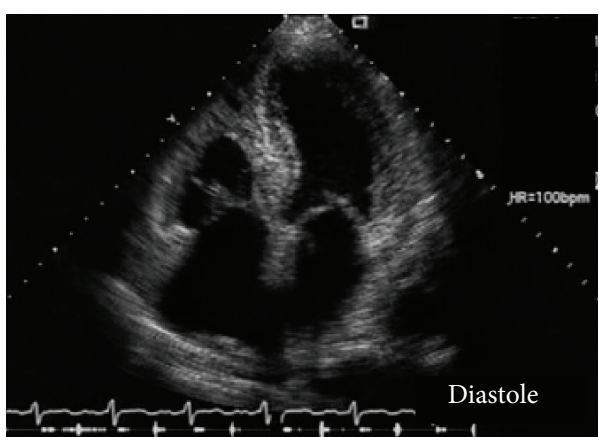

(a)

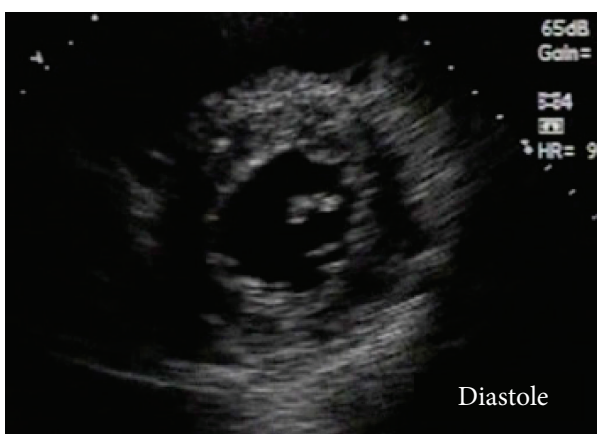

(c)

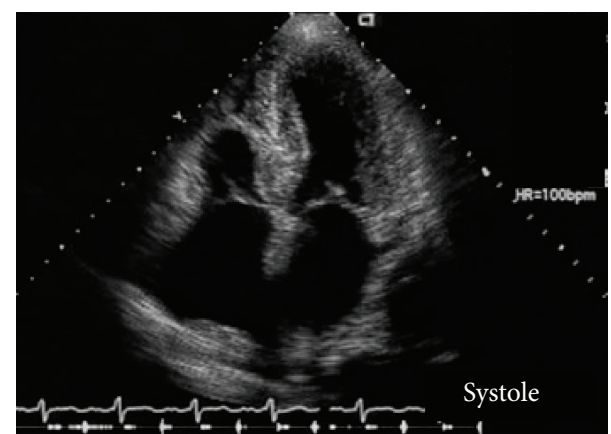

(b)

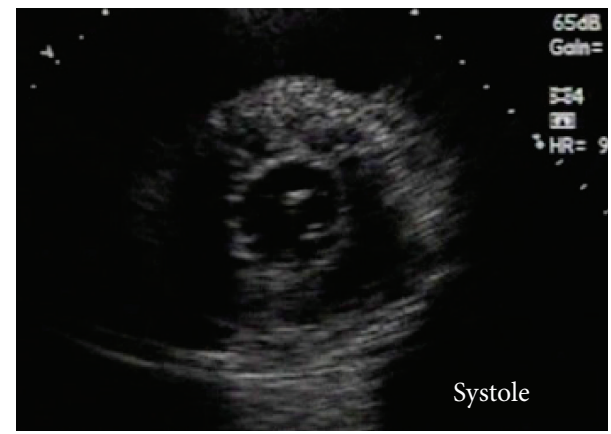

(d)

FIGURE 2: Transthoracic echocardiography 4-chamber ( $\mathrm{a}$ and b) and short axis (c and d) views show concentric left ventricular (LV) hypertrophy, with a sparkling and granular myocardial texture; right ventricular hypertrophy; and bilateral atrial dilatation. The LV ejection fraction is preserved at $53 \%$, and the mass significantly increased to $256.6 \mathrm{~g}$.

heart failure also gradually improved. However, 1 year after the TCZ treatments, hemodialysis was initiated because of worsening fluid retention and renal dysfunction.

The TCZ treatment generally controlled the patient's SAA levels, although there were slight SAA level elevations when she temporarily discontinued TCZ treatment due to a urinary tract infection (Figure 4). She did not experience a relapse of heart failure, and her B-type natriuretic peptide concentration was maintained between 200 and $300 \mathrm{pg} / \mathrm{mL}$.

A second endoscopic gastric biopsy, performed 3 years after the initiation of TCZ treatments, revealed the regression of the amyloid deposition (Figure 1(b)). A follow-up echocardiogram revealed that the patient's LV ejection fraction had increased to $62 \%$ and her left atrial dilatation had improved to $47 \mathrm{~mm}$. The LV mass had minimally decreased to $230 \mathrm{~g}$. We also performed a second renal biopsy to evaluate the possibility of withdrawing the patient from hemodialysis because her urinary volume was preserved at 300-500 mL/day, her gastric manifestations had significantly improved, and her heart failure remained well controlled. However, the second renal biopsy revealed that the amyloid deposition had not regressed and that her global glomerular sclerosis had progressed to 


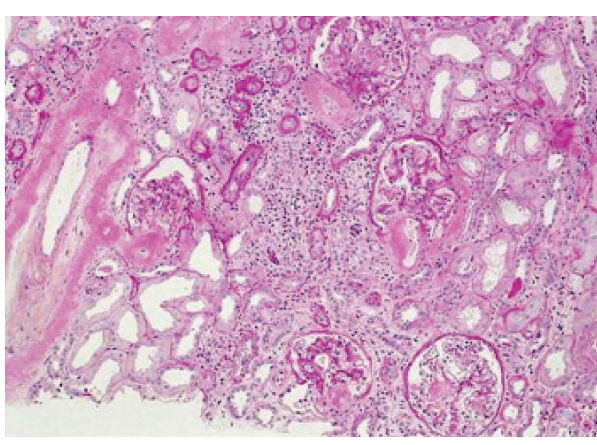

(a)

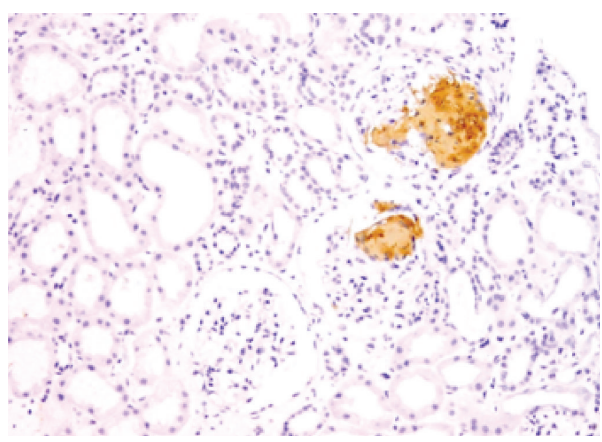

(c)

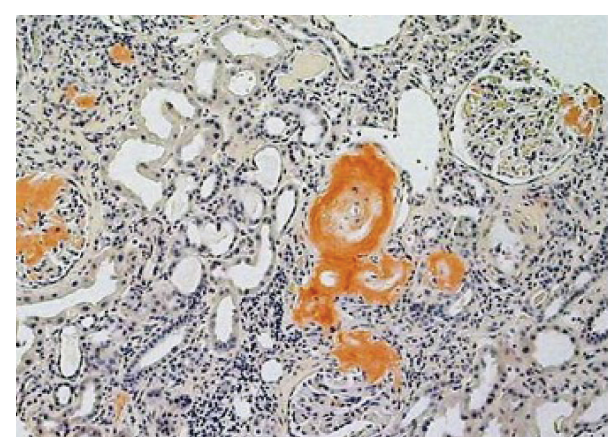

(b)

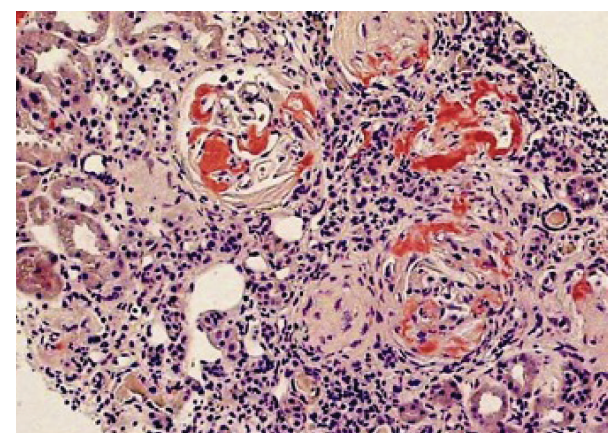

(d)

Figure 3: Renal biopsy. (a) Hematoxylin-eosin staining shows that approximately $40 \%$ of the glomeruli were globally sclerotic; however, the remaining glomeruli were minimally obliterated by mesangial matrix expansion, and homogeneous and eosinophilic deposits were evident along the capillary walls. Small arteries are thickened by eosinophilic deposits, and tubules are focally atrophic. (b) The deposits reveal positive reactions to Congo red. (c) Immunoperoxidase staining confirmed that the deposits included amyloid A protein. (d) After 4 years of tocilizumab treatments, Congo red staining revealed no regression of the amyloid deposition.

approximately $70 \%$ of the glomeruli (Figure 3(d)). Currently, the patient is in good general condition.

\section{Discussion}

We report a patient with AA amyloidosis who was treated with TCZ. After treatment, her gastric manifestations improved significantly, but her renal amyloid deposition did not regress. This suggests two important points regarding TCZ treatment for AA amyloidosis. First, the therapeutic effects of TCZ can vary among different organs in patients with AA amyloidosis, as with the other disease modifying antirheumatic drugs (DMARDs) such as cyclophosphamide and tacrolimus [11]. Thus, a therapeutic benefit of TCZ in one involved organ should not be assumed to be similar in another organ; individual organ assessment is required. Second, TCZ treatments cannot always eliminate renal amyloid deposits in patients with AA amyloidosis. Recent case reports have revealed that TCZ treatments decrease proteinuria and improve or preserve renal function in patients with renal AA amyloidosis [8, 12-14]; however, the present patient's renal involvement was refractory to TCZ treatment.

We speculate that the following are three possibilities for the failure of TCZ to improve the present patient's renal symptoms. First, the removal efficiency of renal amyloid

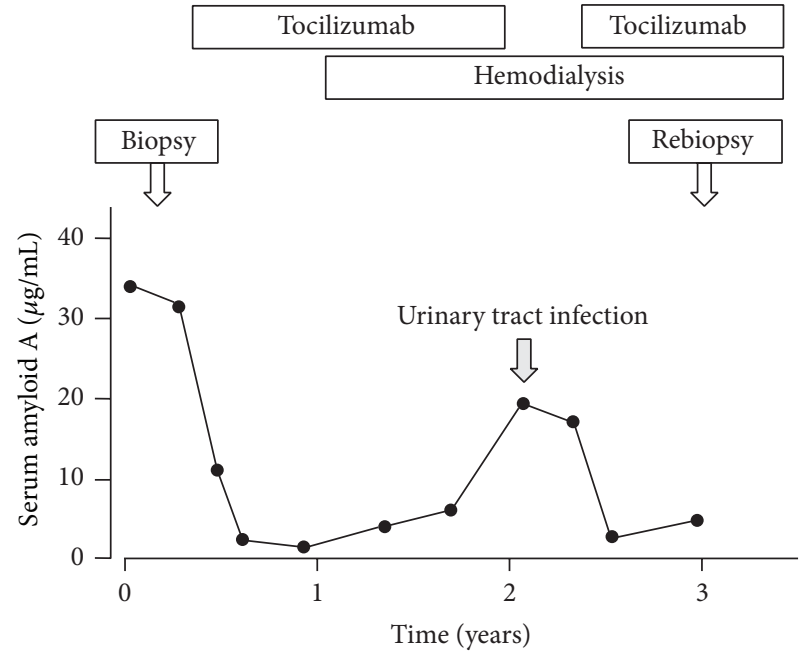

FIgURE 4: The clinical course and the changes of patient's serum amyloid A (SAA) levels. The tocilizumab treatment controlled her SAA levels, although there were transient SAA level elevations due to a urinary tract infection.

deposition may be strongly influenced by the renal damage severity. The present patient's eGFR was significantly decreased compared to that of patients in the previously 
mentioned case reports. Adequate treatment, including TCZ, is essential at an early stage for successful management of renal AA amyloidosis [13]. Second, the renal location of the amyloid deposition might be different in our patient and the previously reported patients. The clinical presentation and prognosis of renal AA amyloidosis were reportedly associated with whether the amyloid deposited predominantly in the glomeruli or in the vessels $[15,16]$. Moreover, therapeutic response of DMARDs may vary among different renal cell types in patients with AA amyloidosis. Falck et al. first demonstrated that renal amyloid deposits were resolved in a case with renal AA amyloidosis during 2-year treatment with cyclophosphamide, using light, electron, and immunofluorescence microscopy [17]. They described that the mesangial amyloid substance is degraded to granular material and that the subepithelial amyloid deposits are resolved by mechanisms similar to those involved in the resolution of subepithelial immune complex deposits. Finally, the regression of renal amyloid deposition may require long-term treatment with TCZ because tissue turnover is considerably slower in the kidney than in the gastric mucosa. Further investigation in patients with renal AA amyloidosis is required to determine the therapeutic effects of TCZ.

Cardiac deposition is rare in patients with AA amyloidosis, and this presentation is associated with a poor prognosis $[18,19]$. We suspected that the present patient had cardiac amyloidosis on the basis of the presence of LV hypertrophy with granular-sparkling myocardial texture, in the absence of other cardiac or systemic diseases [20]. However, we could not make a definite diagnosis because of the absence of histologic confirmation. From the present case, conclusions cannot be drawn regarding the therapeutic effects of TCZ on cardiac amyloidosis. Davis et al. reported that RA patients frequently have preserved ejection fraction at the first diagnosis of heart failure and that their prognosis following onset of heart failure is poor compared with non-RA patients [21]. Thus, our patient should be carefully followed up, regardless of whether she has cardiac amyloidosis.

In conclusion this experience suggests that, in patients with AA amyloidosis, the therapeutic effects of TCZ can differ in different organs. Thus, each involved organ should be individually assessed for therapeutic effect.

\section{Conflict of Interests}

The authors declare that there is no conflict of interests regarding the publication of this paper.

\section{Acknowledgments}

This work was supported in part by grants-in-aid from the Ministry of Health, Labor, and Welfare of Japan and Takeda Science Foundation.

\section{References}

[1] R. H. Falk, R. L. Comenzo, and M. Skinner, "The systemic amyloidoses," New England Journal of Medicine, vol. 337, no. 13, pp. 898-909, 1997.
[2] K. Hagihara, T. Nishikawa, T. Isobe, J. Song, Y. Sugamata, and K. Yoshizaki, "IL-6 plays a critical role in the synergistic induction of human serum amyloid a (SAA) gene when stimulated with proinflammatory cytokines as analyzed with an SAA isoform real-time quantitative RT-PCR assay system," Biochemical and Biophysical Research Communications, vol. 314, no. 2, pp. 363369, 2004.

[3] T. Nakamura, "Clinical strategies for amyloid A amyloidosis secondary to rheumatoid arthritis," Modern Rheumatology, vol. 18, no. 2, pp. 109-118, 2008.

[4] A. Sebba, "Tocilizumab: the first interleukin-6-receptor inhibitor," The American Journal of Health-System Pharmacy, vol. 65, no. 15, pp. 1413-1418, 2008.

[5] Y. Okuda and K. Takasugi, "Successful use of a humanized antiinterleukin-6 receptor antibody, tocilizumab, to treat amyloid A amyloidosis complicating juvenile idiopathic arthritis," Arthritis \& Rheumatism, vol. 54, no. 9, pp. 2997-3000, 2006.

[6] H. Sato, T. Sakai, T. Sugaya et al., “Tocilizumab dramatically ameliorated life-threatening diarrhea due to secondary amyloidosis associated with rheumatoid arthritis," Clinical Rheumatology, vol. 28, no. 9, pp. 1113-1116, 2009.

[7] S. Nishida, K. Hagihara, Y. Shima et al., "Rapid improvement of AA amyloidosis with humanised anti-interleukin 6 receptor antibody treatment," Annals of the Rheumatic Diseases, vol. 68, no. 7, pp. 1235-1236, 2009.

[8] C. Magro-Checa, A. Navas-Parejo Casado, E. Borrego-García et al., "Successful use of Tocilizumab in a patient with nephrotic syndrome due to a rapidly progressing AA amyloidosis secondary to latent tuberculosis," Amyloid, vol. 18, no. 4, pp. 235239, 2011.

[9] Y. Hattori, Y. Ubara, K. Sumida et al., “Tocilizumab improves cardiac disease in a hemodialysis patient with AA amyloidosis secondary to rheumatoid arthritis," Amyloid, vol. 19, no. 1, pp. $37-40,2012$.

[10] R. B. Devereux, D. R. Alonso, and E. M. Lutas, "Echocardiographic assessment of left ventricular hypertrophy: comparison to necropsy findings," The American Journal of Cardiology, vol. 57, no. 6, pp. 450-458, 1986.

[11] T. Ueno, K. Takeda, and M. Nagata, "Remission of proteinuria and preservation of renal function in patients with renal AA amyloidosis secondary to rheumatoid arthritis," Nephrology Dialysis Transplantation, vol. 27, no. 2, pp. 633-639, 2012.

[12] S. Hasegawa, A. Sato, K. Iesato, and Y. Matsuda, "Case report; a case of rheumatoid arthritis with renal amyloidosis and nephrotic syndrome effectively treated with tocilizumab," Nihon Naika Gakkai Zasshi, vol. 100, no. 1, pp. 185-187, 2011.

[13] M. Hakala, K. Immonen, M. Korpela, M. Vasala, and M. J. Kauppi, "Good medium-term efficacy of tocilizumab in DMARD and anti-TNF- $\alpha$ therapy resistant reactive amyloidosis," Annals of the Rheumatic Diseases, vol. 72, no. 3, pp. 464465, 2013.

[14] N. Otani, Y. Morishita, I. Oh et al., "Successful treatment of a mesangial proliferative glomerulonephritis with interstitial nephritis associated with Castleman's disease by an anti-interleukin-6 receptor antibody (tocilizumab)," Internal Medicine, vol. 51, no. 11, pp. 1375-1378, 2012.

[15] H. Shiiki, T. Shimokama, Y. Yoshikawa, H. Toyoshima, T. Kitamoto, and T. Watanabe, "Renal amyloidosis: correlations between morphology, chemical types of amyloid protein and clinical features," Virchows Archiv: A Pathological Anatomy and Histopathology, vol. 412, no. 3, pp. 197-204, 1988. 
[16] L. M. Looi, "Histmorphological variations in systemic AA amyloidosis: clues of AA protein polymorphism," Histopathology, vol. 14, no. 2, pp. 111-120, 1989.

[17] H. M. Falck, T. Tornroth, B. Skrifvars, and O. Wegelius, "Resolution of renal amyloidosis secondary to rheumatoid arthritis," Acta Medica Scandinavica, vol. 205, no. 7, pp. 651-656, 1979.

[18] S. W. Dubrey and R. L. Comenzo, "Amyloid diseases of the heart: current and future therapies," QJM, vol. 105, no. 7, pp. 617-631, 2012.

[19] H. J. Lachmann, H. J. B. Goodman, J. A. Gilbertson et al., "Natural history and outcome in systemic AA amyloidosis," New England Journal of Medicine, vol. 356, no. 23, pp. 2361-2371, 2007.

[20] A. G. Siqueira-Filho, C. L. P. Cunha, A. J. Tajik, J. B. Seward, T. T. Schattenberg, and E. R. Giuliani, "M-mode and twodimensional echocardiographic features in cardiac amyloidosis," Circulation, vol. 63, no. 1, pp. 188-196, 1981.

[21] J. M. Davis III, V. L. Roger, C. S. Crowson, H. M. Kremers, T. M. Therneau, and S. E. Gabriel, "The presentation and outcome of heart failure in patients with rheumatoid arthritis differs from that in the general population," Arthritis and Rheumatism, vol. 58, no. 9, pp. 2603-2611, 2008. 


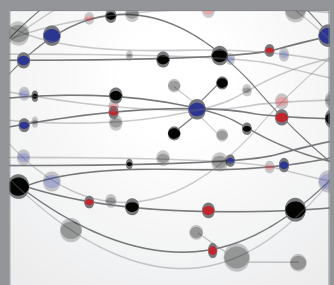

The Scientific World Journal
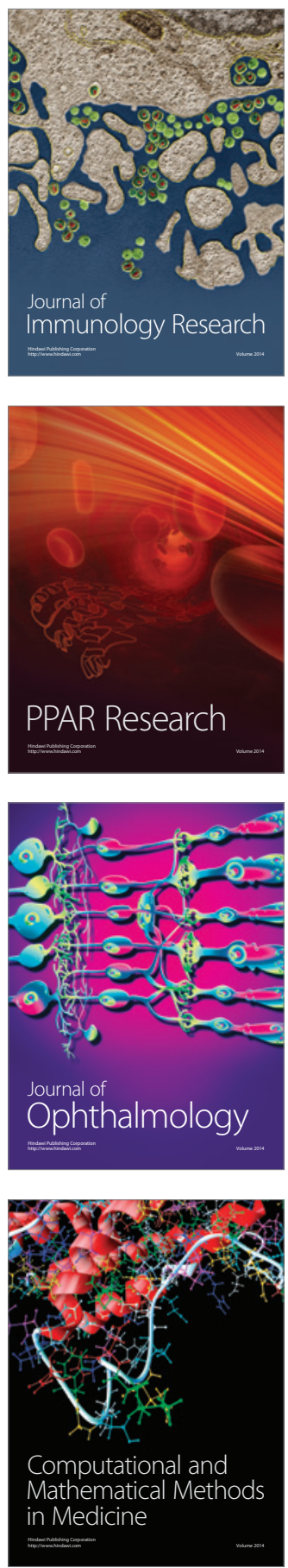

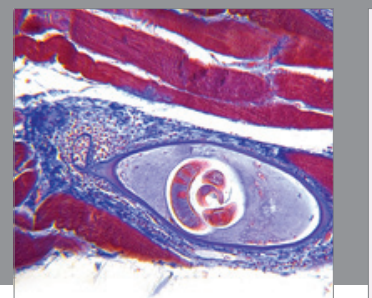

Gastroenterology

Research and Practice
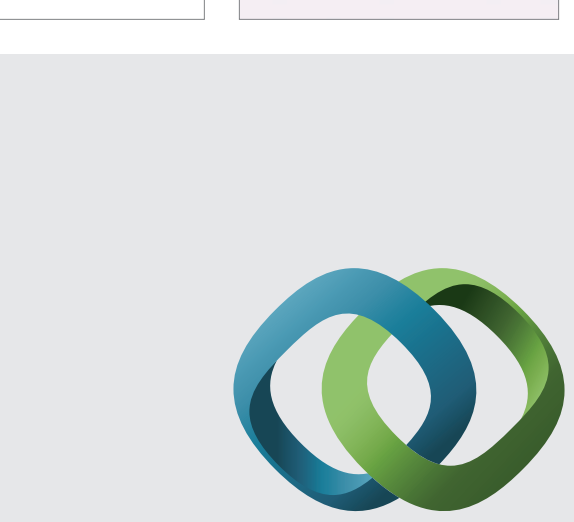

\section{Hindawi}

Submit your manuscripts at

http://www.hindawi.com
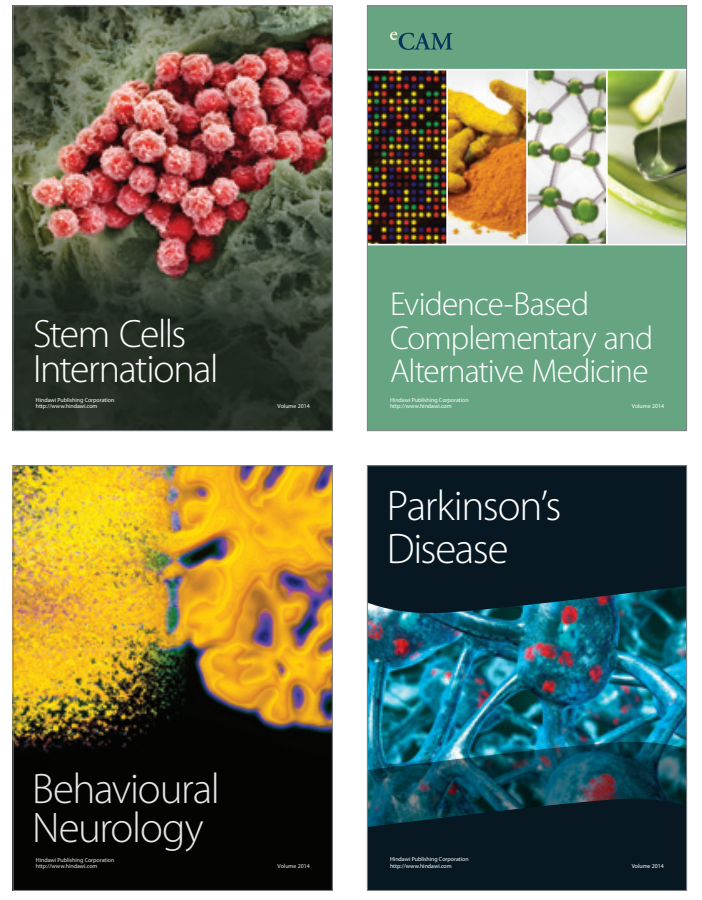
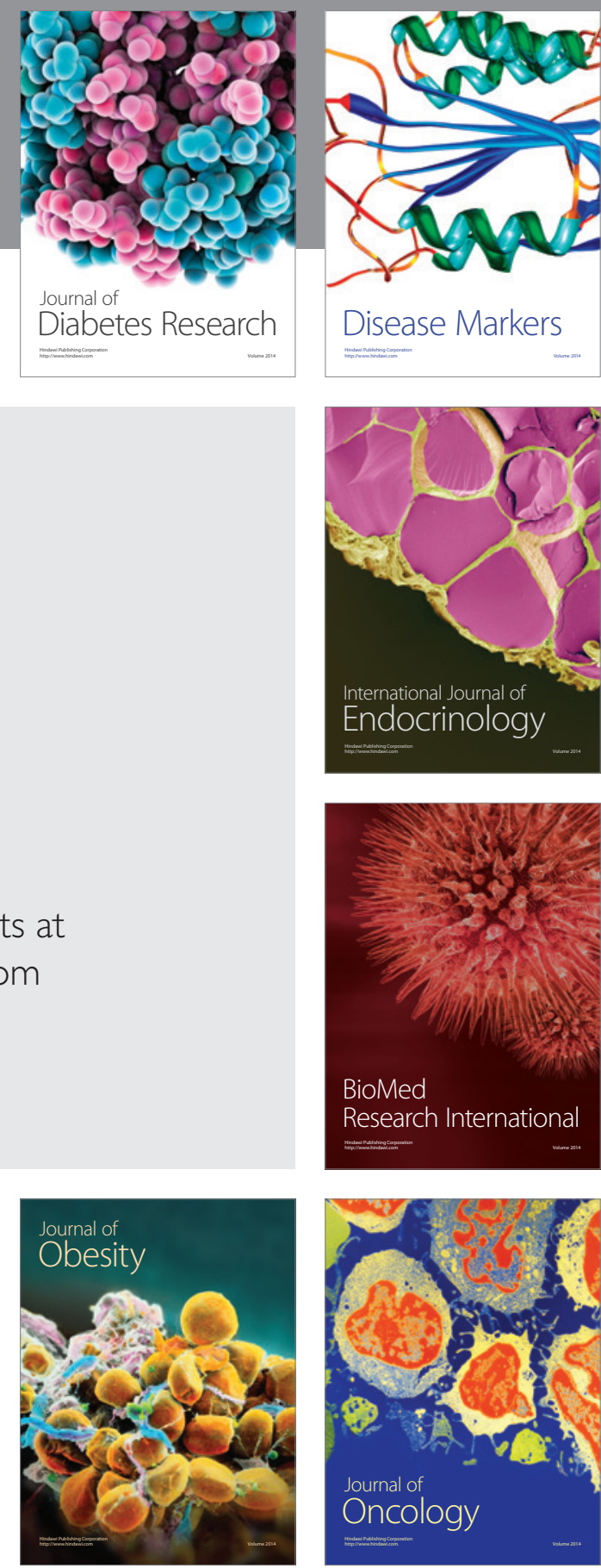

Disease Markers
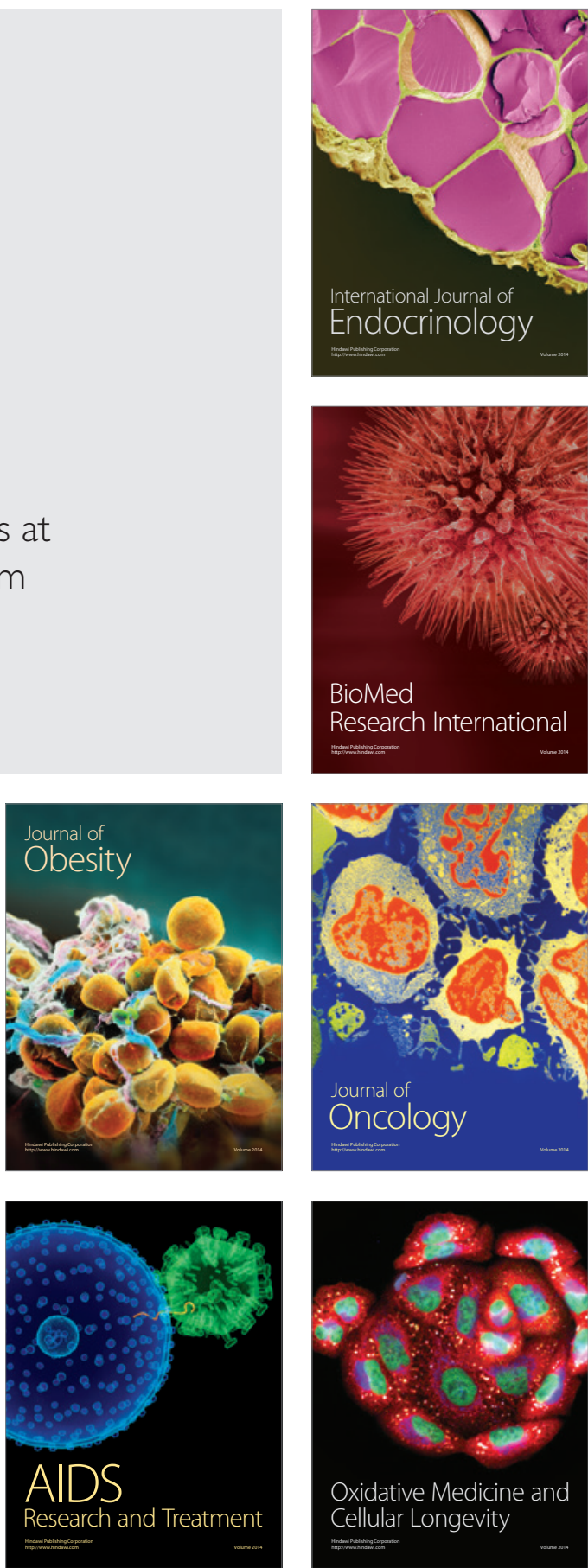